\title{
Impact of stress and levels of corticosterone on the development of breast cancer in rats
}

This article was published in the following Dove Press journal:

Psychology Research and Behavior Management

5 January 2016

Number of times this article has been viewed

\author{
José María De la Roca- \\ Chiapas' \\ Gloria Barbosa-Sabanero \\ Jorge Antonio Martínez- \\ García $^{3}$ \\ Joel Martínez-Soto' \\ Víctor Manuel Ramos- \\ Frausto' \\ Leivy Patricia González- \\ Ramírez' \\ Ken Nowack ${ }^{4}$ \\ 'Department of Psychology, \\ ${ }^{2}$ Department of Medical Sciences, \\ Division of Health Sciences, Campus \\ Leon-University of Guanajuato, \\ Guanajuato, ${ }^{3}$ General Regional \\ Hospital of Leon, Guanajuato, Mexico; \\ ${ }^{4}$ Envisia Learning, Inc., Santa Monica, \\ CA, USA
}

\begin{abstract}
Stress is experienced during cancer, and impairs the immune system's ability to protect the body. Our aim was to investigate if isolation stress has an impact on the development of tumors in rats, and to measure the size and number of tumors and the levels of corticosterone. Breast cancer was induced in two groups of female rats $(\mathrm{N}=20)$ by administration of a single dose of $N$-methyl- $N$-nitrosourea $50 \mathrm{mg} / \mathrm{kg}$. Rats in the control group (cancer induction condition) were allowed to remain together in a large cage, whereas in the second group, rats were also exposed to a stressful condition, that is, isolation (cancer induction and isolation condition, CIIC). The CIIC group displayed anxious behavior after 10 weeks of isolation. In the CIIC group, 16 tumors developed, compared with only eleven tumors in the control cancer induction condition group. In addition, compared with the control group, the volume of tumors in the CIIC group was greater, and more rats had more than one tumor and cells showed greater morphological damage. Levels of corticosterone were also significantly different between the two groups. This study supports the hypothesis that stress can influence the development of cancer, but that stress itself is not a sufficient factor for the development of cancer in rats. The study also provides new information for development of experimental studies and controlled environments.
\end{abstract}

Keywords: breast cancer, corticosterone, isolation condition, psychoneuroimmunology, stress

\section{Introduction}

Stress is not an external stimulus, but rather an internal reaction of an organism to its environment. ${ }^{1}$ Stress can be positive (eustress), as in conditions of danger, when the body reacts with alert behavior. By contrast, negative stress or "distress" occurs when the activation, intensity, and persistence of the stress results in physical and psychological disorders. ${ }^{2,3}$

Various studies have shown an association between stress and cancer and investigated the multiple effects exerted by stress on immune function; for example, during the diagnosis and treatment of the disease, some patients experience stress and depression that result in immune suppression. ${ }^{4-8}$ Similarly, patients with breast cancer have a decrease in their numbers of natural killer cells, and alterations in the secretion of cytokines ${ }^{9}$ and in DNA repair capacity. ${ }^{10-12}$ It has been shown in vitro that stress is involved in pathways of cancer progression such as immunoregulation, angiogenesis, and invasion. ${ }^{13}$

During stress, the brain, endocrine system, and immune system form a circuit, communicating through systems such as neurotransmitters, neuropeptides, hormones, lymphoid tissue growth factors, cytokines, and eicosanoids. ${ }^{8}$ Psychoneuroimmunology studies have revealed how much the immune system is affected by the influence of stress. The reactions are complex, involving different tissues and body system responses. ${ }^{14,15}$ 
The target organ responding to stress is the brain, and it determines the activity of other tissues by the action of hormones and immune receptors on pathway that alter brain function and regulate stress response. The physiological changes caused by stress are crucial, and the major components in these changes are corticotropin-releasing factor and the locus coeruleus of the brain. ${ }^{16}$

The immune system is highly sensitive to changes in the body and the stimuli to which it is exposed. Immune function is often diminished by psychological stress, ${ }^{8}$ but increases as a result of significant and positive events. ${ }^{17,18}$ Social support has been shown to be a factor that improves the outcome of patients with cancer, and may produce a better immune response, as it reduces the level of cortisol and restores the natural killer cell number and production of cytokines, $9,11,19,20$ whereas social isolation increases the risk of death associated with several chronic diseases. ${ }^{6}$

The $N$-methyl- $N$-nitrosourea (NMU) rat model used in this study is considered to be one of the best animal models of cancer. Chemical induction of mammary cancer in rats has a number of features that make it very useful for investigating many aspects of breast cancer, for instance: 1) the time to tumor development is short; 2) tumors are generated mainly in the mammary gland (adenocarcinomas) as the cancer has limited metastatic potential; 3 ) the carcinogen causes little or no systemic toxic effect; and 4) the breast tumors produced have histologic origin and pathologic features that are similar to those of typical human breast cancer. ${ }^{21,22}$ In this model, we used a single intraperitoneal dose of $50 \mathrm{mg}$ NMU/kg body weight. ${ }^{21}$ In addition, the stress induced by isolation condition has some theoretical support, applicable to studies of live rodents, ${ }^{5,23-25}$ and producing multiple physiological changes and behavioral effects. ${ }^{8,25}$ Finally, changes in tumor volume in animal models are often used to evaluate the effects of different factors on mammary gland carcinogenesis in female rats, because they may have important prognostic value for some malignancies, including breast cancer. ${ }^{26}$

The objective of this study was to investigate whether stress caused by isolation of rats has an impact on the development of tumors, assessed by the volume and number of tumors, and the levels of corticosterone.

\section{Methods}

\section{Animals}

Breast cancer was induced by intraperitoneal administration of a single dose of $50 \mathrm{mg} \mathrm{NMU} / \mathrm{kg}$ body weight in

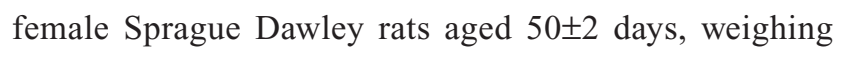
$90 \pm 15 \mathrm{~g}(\mathrm{~N}=20) .{ }^{27}$ This strain was chosen because studies have shown that it is an excellent model for the development and progression of breast cancer, as the rats naturally develop a diagnostic range similar to humans. ${ }^{23,28}$

\section{Induction of cancer in rats}

The carcinogen NMU (catalog number 684/93/5, product number N1517-isopac, PubChem Substance ID 24897498; Sigma, St Louis, MO, USA) is a model for chemical induction of mammary cancer in rats. It is an alkylating agent that acts directly on DNA, creating mutations. ${ }^{29}$

\section{Induction of stress in rats}

A method for inducing stress by social isolation or deprivation was chosen. This model consists of isolating each of the rats in a cage, preventing any kind of social interaction with their peers, which leads to a pattern of apathy and chronic stress after approximately 10 weeks. ${ }^{24,25}$

\section{Procedure}

Twenty Sprague Dawley rats were injected with the carcinogen NMU. ${ }^{21}$ At $51 \pm 2$ days, the animals were divided into two groups of ten rats each. Rats belonging to the control group (cancer induction condition group) were allowed to remain together in a large cage, while the study group were exposed to both cancer induction and isolation stress (cancer induction and isolation condition, CIIC), so they were placed in individual cages, $12.5 \times 14.5 \times 26.5 \mathrm{~cm}$ in size, preventing social interaction with their peers. At 5 months of age, all rats were euthanized and the tumors removed. Tumor size was estimated using a Vernier caliper by two different methods: 1) taking into account only the larger diameter and 2) measuring three dimensions to give the approximate total volume. TNM classification was used (classification of the primary tumor size [T], node status or regional lymph nodes $[\mathrm{N}]$, and the presence of distant metastasis [M]). ${ }^{30}$

Cancer type was confirmed by histopathological examination of paraffin wax-embedded sections from tumors of each subset of animals. Mammary tumors were classified according to Russo et al. ${ }^{31}$ Corticosterone quantification was performed by enzyme-linked immunosorbent assay using a commercial kit (Alpco, Salem, NH, USA, catalog number 55-CORMS-E01).

\section{Statistical analysis}

To assess the heterogeneity of the groups when comparing the number, diameter, and approximate total volume of the tumors that developed in the group, we used nonparametric analysis with the Mann-Whitney $U$-test for independent samples. We also used $t$-test for independent samples testing of corticosterone in rats. 


\section{Ethics}

This study was approved by the Ethics Committee of the Department of Medical Sciences, University of Guanajuato. This study followed the criteria required by the Official Mexican Standard NOM-062-ZOO-1999 regarding animal husbandry (characteristics that comprise the laboratory animal research, the staff responsible for operational processes, the profile of technical staff involved in the care and use of the laboratory animals, obtaining of the animals, health and quality certificate, and the identification and registration of the thereof). ${ }^{32}$

\section{Results}

It was observed that after 70 days, $100 \%$ of the rats that had received an injection of the carcinogen had developed at least one tumor. At the time of euthanasia, the control group had developed eleven tumors; nine rats $(90 \%)$ had one tumor each, and one rat (10\%) developed two tumors. By contrast, the rats in the experimental CIIC group had 16 tumors; six rats $(60 \%)$ developed one tumor, two rats $(20 \%)$ developed two tumors, and two rats $(20 \%)$ developed three tumors. As shown in Table 1, the CIIC group tended to have a larger tumor volume, and more rats had more than one tumor, compared with the control group.

The between-group comparison groups revealed no significant differences in: 1) number of tumors or 2) the two methods of estimating tumor size used: i) larger diameter and ii) approximate volume of the tumors (Table 2).

Level of corticosterone was significantly different between the CIIC and control groups ( $t=2.50 ; P=0.02)$. Higher corticosterone levels were found in the CIIC $(1058.57 \mathrm{ng} / \mathrm{mL} \pm$ standard error [SE] 1.96) than in the control $(599.7 \mathrm{ng} / \mathrm{mL} \pm$ SE 1.96) group (Figure 1). The normal range of serum corticosterone in female rats is $292.5-819.0 \mathrm{ng} / \mathrm{mL}{ }^{33}$

Table I Number, diameter, and volume of tumors in both rat groups

\begin{tabular}{lll}
\hline Parameter & $\begin{array}{l}\text { Cancer } \\
\text { (control) group } \\
\text { (mean } \pm \text { SD) }\end{array}$ & $\begin{array}{l}\text { Cancer }+ \\
\text { stress group } \\
\text { (mean } \pm \text { SD) }\end{array}$ \\
\hline $\begin{array}{l}\text { Number of tumors } \\
\text { Number of tumors with larger than } \\
\text { average diameter }\end{array}$ & $\begin{array}{l}1.1 \pm 0.31 \\
1.62 \pm 2.27\end{array}$ & $2.5 \pm 0.84$ \\
$\begin{array}{l}\text { Number of tumors with larger than } \\
\text { average diameter without outliers }\end{array}$ & $1.99 \pm 0.88$ & $2.19 \pm 1.30$ \\
$\begin{array}{l}\text { Approximate average total volume } \\
\text { of tumors }\end{array}$ & $7.06 \pm 7.07$ & $24.65 \pm 67.85$ \\
$\begin{array}{l}\text { Approximate average total volume } \\
\text { of tumors without outliers }\end{array}$ & $5.56 \pm 5.30$ & $7.93 \pm 11.72$ \\
\hline
\end{tabular}

Abbreviation: SD, standard deviation.
Table 2 Comparison between both groups with the MannWhitney $U$-test, significant difference $P<0.05$

\begin{tabular}{lll}
\hline Parameter & U-value & $P$-value* \\
\hline Number of tumors & 34 & 0.226477 \\
Larger diameter & 87 & 0.960643 \\
Approximate total volume & 43 & 0.596702 \\
\hline
\end{tabular}

Notes: *Mann-Whitney U-test; significant difference $P<0.05$.

Figure 2 shows the histopathologic characteristics of representative tumors from each of the groups. The CIIC group exhibited cells with increased nuclear/cytoplasmic ratio, indicating a more active process of division, which is a morphological criteria of malignancy. Further, to demonstrate the capacity of mammary tumor cells to respond to corticosterone, we performed immunohistochemistry and found that rat mammary tumors, including benign fibroadenomas, ductal carcinoma in situ, and invasive ductal carcinoma all expressed glucocorticoid receptors.

Rats in the CIIC group also showed apathetic behavior (eg, stopped eating) and appeared fearful.

\section{Discussion}

The main objective of this research was to investigate whether stress caused by isolation could affect the development and size of tumors and the levels of corticosterone in rats. There were statistically significant differences in corticosterone levels between the two groups. Although both groups showed tumor development, the CIIC group had greater morphological damage, with larger tumor size and a higher number of multicentric tumors in each rat, and also more aggressive activity in invasive cancer as indicated by immunohistochemical studies. Moreover, anxious behavior was evident in the group with insulation. The lack of statistically significant difference may be due to the small size of the sample, causing a possible type II error.

The CIIC group also had higher levels of corticosterone. Similar findings were reported by Hermes et al, ${ }^{23}$ who observed that mice kept in isolation developed significant dysregulation of corticosterone responses, while cancer recovery was markedly delayed, and this was associated with increased mammary tumor progression. Further, to demonstrate the capacity of mammary tumor cells to respond to corticosterone, they performed immunohistochemistry, and found that, rat mammary tumors, including benign fibroadenomas, ductal carcinoma in situ, and invasive ductal carcinoma all expressed glucocorticoid receptors.

Studies have evaluated multifocal and multicentric breast cancer tumors, and using (in addition to the TNM method) the aggregate tumor volume (ie, the summation of the diameter 


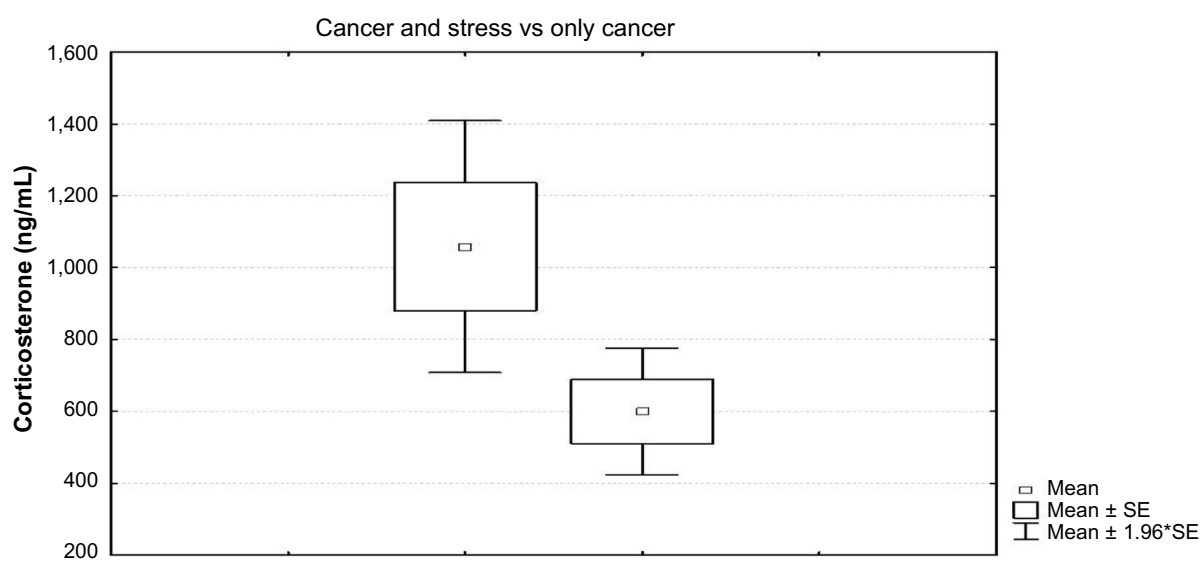

Figure I Comparison between the level of corticosterone in the group with $\mathrm{CIC}$ and $\mathrm{CIIC}$.

Abbreviations: $\mathrm{CIC}$, cancer induction condition; $\mathrm{CIIC}$, cancer induction and isolation condition; SE, standard error; vs, versus.

of all tumors found in a single quadrant or in different quadrants of the breast) have found that tumor size is a variable that can predict the existence of metastases in lymph axillary nodes. ${ }^{34,35}$ One research, however, suggests that the estimate of the approximate total tumor volume is a more successful predictor of metastatic potential than the use of: 1) the largest tumor diameter as the only estimate or 2 ) the aggregate tumor volume. ${ }^{36}$ However, to obtain approximate total tumor volume, it is necessary to measure the tumor in three dimensions (length, width, and depth), and the calculation of the total volume is only possible in objects having regular surfaces. In the current study, we used both the TNM method and measurement of the estimated approximate total volume of the tumor.

During the study, we observed that the behavior of rats in response to isolation stress was different in individual rats; some resisted and struggled, trying to get out of the cage, whereas others showed apathetic behavior (such as ceasing to eat) and appeared fearful. Other studies have observed similar behavior in rats, associated with early exposure to stressors, glucocorticoid dynamics, and subsequent development of mammary tumors and cancer progression. ${ }^{37,38}$

It is likely that the behavioral responses seen in rats in this study are similar to those expressed by humans, although it is easier to control for variables within the laboratory, whereas studies on the influence of stress on cancer in humans relies on subjective evaluation of the event, performed by the individual patient and according to which the patient responds to stress. ${ }^{39}$ However, these findings indicate a necessity to provide psychological and social support, along with strategies for stress reduction, for patients who are given a diagnosis of cancer.
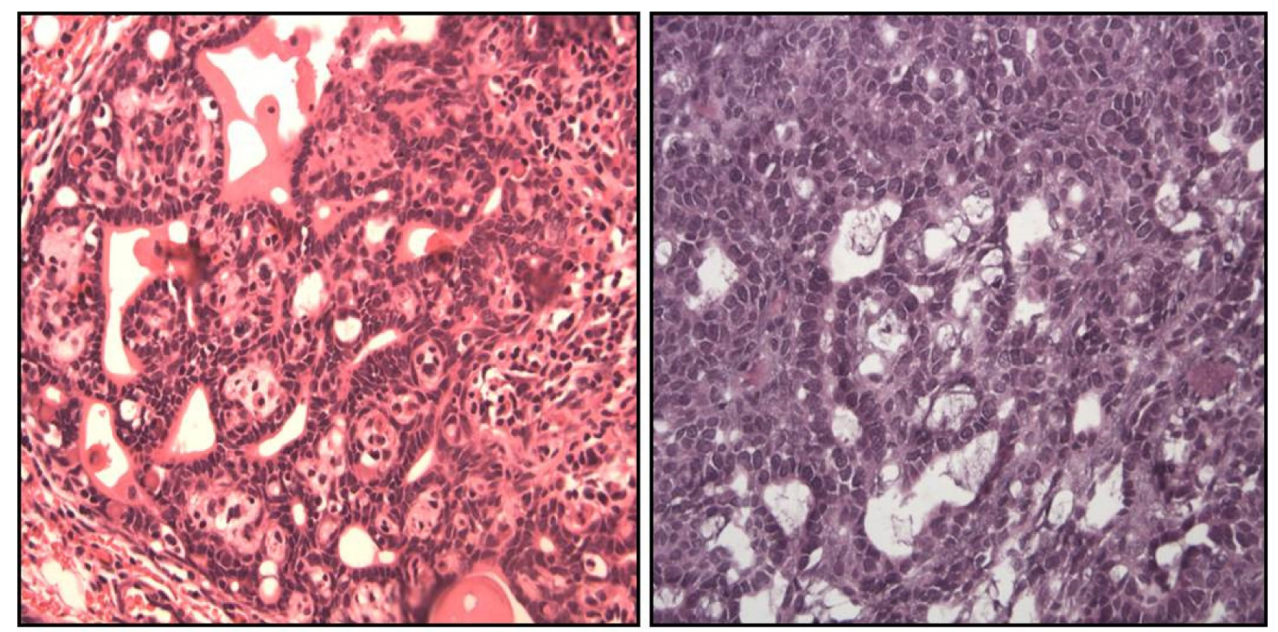

Figure 2 Histopathologic characteristics.

Notes: In the tumor of $\mathrm{CIC}$ group, the neoplastic cells have smaller nucleus and increased tubule formation. Mast cells infiltrating the tumor are observed $(\times 40)$. Tumor of CIIC group shows abundant cellularity (40x), lower degree of histological differentiation, areas more solid without inflammation, cells with larger nucleus and less cytoplasm; indicating a process of division more active.

Abbreviations: $\mathrm{ClC}$, cancer induction condition; CIIC, cancer induction and isolation condition. 
The significant differences in the level of corticosterone seen in the two groups in this study support the hypothesis that stress can influence the development of cancer, but we cannot conclude that stress itself is a sufficient factor for the development of cancer in rats. Therefore, further research is needed to clarify the relationship between stress, the immune system, and cancer, using reliable and innovative experimental methods. Previous findings from various investigations that have studied the relationship between stress, the effects on the immune system, and how both of these influence the progression of cancer are controversial, owing to the complexity of studying these variables, because many factors may converge, and these must be weighed with extreme care.

The results of our study support those of previous studies ${ }^{5,6,23}$ showing that stress influences tumor development, and directly influences tumor size and corticosterone level. They also provide new information for development of controlled environments to measure experimental stress in cancer models and reduce interference from other variables.

\section{Acknowledgment}

This project was supported by Ugto-CA-37 PROMEP funding.

\section{Disclosure}

The authors report no conflicts of interest in this work.

\section{References}

1. Morera A, Gonzalez-de-Rivera JL. Relación entre factores de estrés, depresión y enfermedad médica. Psiquis. 1983;4:253-260.

2. Szabo S. Hans Selye and the development of the stress concept. Special reference to gastroduodenal ulcerogenesis. Ann N Y Acad Sci. 1998;851:19-27.

3. Lopez D. [Stress epidemic of the century: how to understand it and overcome]. Estres Epidemia del Siglo XXI: Como Entenderlo, Entenderse y Vencerlo. 4th ed. Buenos Aires: Lumen; 2005.

4. Sephton SE, Dhabhar FS, Keuroghlian AS, et al. Depression, cortisol, and suppressed cell-mediated immunity in metastatic breast cancer. Brain Behav Immun. 2009;23:1148-1155.

5. Madden KS, Szpunar MJ, Brown EB. Early impact of social isolation and breast tumor progression in mice. Brain Behav Immun. 2013;30: 135-141.

6. Williams JB, McDonough MA, Hilliard MW, Williams AL, Cuniowski PC, Gonzalez MG. Intermethod reliability of real-time versus delayed videotaped evaluation of a high-fidelity medical simulation septic shock scenario. Acad Emerg Med. 2009;16:887-893.

7. Powell ND, Tarr AJ, Sheridan JF. Psychosocial stress and inflammation in cancer. Brain Behav Immun. 2013;30:41-47.

8. Segerstrom SC, Miller GE. Psychological stress and the human immune system: a meta-analytic study of 30 years of inquiry. Psychol Bull. 2004; 130(4):601-630.

9. Witek-Janusek L, Albuquerque K, Chroniak KR, Chroniak C, DurazoArvizu R, Mathews HL. Effect of mindfulness based stress reduction on immune function, quality of life and coping in women newly diagnosed with early stage breast cancer. Brain Behav Immun. 2008;22(6): 969-981.
10. Kiecolt-Glaser JK, Stephens RE, Lipetz PD, Speicher CE, Glaser R. Distress and DNA repair in human lymphocytes. J Behav Med. 1985;8(4):311-320.

11. Kiecolt-Glaser JK, Robles TF, Heffner KL, Loving TJ, Glaser R. Psycho-oncology and cancer: psychoneuroimmunology and cancer. Ann Oncol. 2002;13(Suppl 4):S165-S169.

12. Andersen BL, Farrar WB, Golden-Kreutz D, et al. Stress and immune responses after surgical treatment for regional breast cancer. $J$ Natl Cancer Inst. 1998;90(1):30-36.

13. Lutgendorf SK, Sood AK, Antoni MH. Host factors and cancer progression: biobehavioral signaling pathways and interventions. J Clin Oncol. 2010;28(26):4094-4099.

14. Sánchez M, González RM, Cos Y, Macías C. [Stress and immune system]. Estres y sistema inmune. Rev Cubana Hematol Inmunol Hemoter. 2007;23.

15. Vera-Vaillarroel PE, Vela-Casal G. [Psychoneuroimmunology: relationships between psychological and immunological human factors]. Psiconeuroinmunología: relaciones entre factores psicológicos e inmunitarios en humanos. Rev Latinoam Psicol. 1999;31(2):271-289.

16. Orlandini A. [Stress: What is and how to avoid it. Mexico: Economic Culture Fund]. El Estres: Que es y como evitarlo. México: Fondo de Cultura Economica; 1999.

17. Reiche EM, Nunes SO, Morimoto HK. Stress, depression, the immune system, and cancer. Lancet Oncol. 2004;5(10):617-625.

18. Sirera R, Sánchez P, Camps C. Inmunología, estres, depresion y cancer. Psicooncologia. 2006;3:35-48.

19. Blomberg BB, Alvarez JP, Diaz A, et al. Psychosocial adaptation and cellular immunity in breast cancer patients in the weeks after surgery: an exploratory study. J Psychosom Res. 2009;67(5):369-376.

20. Antoni MH, Lechner S, Diaz A, et al. Cognitive behavioral stress management effects on psychosocial and physiological adaptation in women undergoing treatment for breast cancer. Brain Behav Immun. 2009;23(5):580-591.

21. Garcia-Solis P, Aceves C. [Study of nutritional factors associated with the prevention of breast cancer. Importance of animal models]. Estudio de los factores nutricionales asociados a la prevención de cáncer mamario. Importancia de los modelos animales. Arch Latinoam Nutr. 2005;55:211-225

22. De la Roca-Chiapas JM, Cordova-Fraga T, Sabanero GB, et al. Aplicaciones interdisciplinaria entre fisica, medicina y psicologia. Acta Universitaria. 2009;19:71-75.

23. Hermes GL, Delgado B, Tretiakova M, et al. Social isolation dysregulates endocrine and behavioral stress while increasing malignant burden of spontaneous mammary tumors. Proc Natl Acad Sci U S A. 2009;106(52):22393-22398.

24. Hiscox DN, Husband RF, Perry MC. Survival, bodyweight and food consumption data obtained from life span rodent studies in isolated animal units. Arch Toxicol Suppl. 1983;6:357-360.

25. Takemoto TI, Suzuki T, Miyama T. Effects of isolation on mice in relation to age and sex. Tohoku J Exp Med. 1975;117(2):153-165.

26. Môciková k, Mníchova M, Kubatka P, Bojková B, Ahlers I, Ahlersová E. Mammary carcinogenesis induced in WistanHan rats by the combination of ionizing radiation and dimethylbenz (a) anthracene: prevention with melatonin. Neoplasma. 2000;47(4):227-229.

27. Garcia-Solis P, Alfaro Y, Anguiano B, et al. Inhibition of N-methyl-Nnitrosourea-induced mammary carcinogenesis by molecular iodine (I2) but not by iodide (I-) treatment: evidence that $\mathrm{I} 2$ prevents cancer promotion. Mol Cell Endocrinol. 2005;236(1-2):49-57.

28. Davis RK, Stevenson GT, Busch KA. Tumor incidence in normal Sprague-Dawley female rats. Cancer Res. 1956;16(3):194-197.

29. Thompson H. Methods for the induction of mammary carcinogenesis in the rat using either 7,12-Dimethylbenz[ $\alpha]$ anthracene or 1-methyl1-nitrosurea. In: Methods in Mammary Gland Biology and Breast Cancer Research. New York: Kluwer Academic/Plenum Publishers; 2000:19-29.

30. Green FL. AJCC Cancer Staging Handbook: from the AJCC Cancer Staging Manual. 6th ed. New York: Springer; 2002. 
31. Russo J, Russo IH, Rogers AE, Van Zwieten MJ, Gusterson B. Tumors of mammary gland. In: Turusov V, Mohr U, editors. Pathology of Tumours in Laboratory Animals. Lyon: IARC Scientific Publications; 1990:1:47-78.

32. NOM-062-ZOO-1999, NORMA Oficial Mexicana NOM-062ZOO-1999. [Technical specifications for production, care and use of animals of laboratory]. Especificaciones Tecnicas Para La Produccion, Cuidado Y Uso De Los Animales De Laboratorio. Mexico; 1999.

33. ALPCO, mouse and rat corticosterone ELISA. For the quantitative determination of corticosterone in rat and mouse serum or plasma. Catalog number: 55-CORMS-E01 2013.

34. Coombs NJ, Boyages J. Multifocal and multicentric breast cancer: does each focus matter? J Clin Oncol. 2005;23(30):7497-7502.

35. Andea AA, Wallis T, Newman LA, Bouwman D, Dey J, Visscher DW. Pathologic analysis of tumor size and lymph node status in multifocal/ multicentric breast carcinoma. Cancer. 2002;94(5):1383-1390.
36. Andea AA, Bouwman D, Wallis T, Visscher DW. Correlation of tumor volume and surface area with lymph node status in patients with multifocal/multicentric breast carcinoma. Cancer. 2004;100(1):20-27.

37. Cavigelli SA, Yee JR, McClintock MK. Infant temperament predicts life span in female rats that develop spontaneous tumors. Horm Behav. 2006;50(3):454-462.

38. Yee JR, Cavigelli SA, Delgado B, McClintock MK. Reciprocal affiliation among adolescent rats during a mild group stressor predicts mammary tumors and lifespan. Psychosom Med. 2008;70(9):1050-1059.

39. McEwen BS. Protective and damaging effects of stress mediators. N Engl J Med. 1998;338(3):171-179.

\section{Publish your work in this journal}

Psychology Research and Behavior Management is an international, peerreviewed, open access journal focusing on the science of psychology and its application in behavior management to develop improved outcomes in the clinical, educational, sports and business arenas. Specific topics covered include: Neuroscience, memory \& decision making; Behavior modification \& management; Clinical applications; Business \& sports performance management; Social and developmental studies; Animal studies. The manuscript management system is completely online and includes a quick and fair peer-review system. Visit http://www.dovepress. com/testimonials.php to read real quotes from published authors.

\footnotetext{
Submit your manuscript here: http://www.dovepress.com/psychology-research-and-behavior-management-journal
} 